\title{
A disseminação da informação no Twitter: uma análise exploratória do fluxo informacional de retweets
}

Célio Andrade Santana Júnior, João Pedro Silva Albuquerque, Fabiola Souza Queiroz, Steffane Ramires Lima

\begin{abstract}
Resumo
Introdução: Apresenta o processo de disseminação da informação no serviço de microblog Twitter a partir dos retweets realizados por usuários, que assim disseminam mensagens criadas por perfis. 0 objetivo desta pesquisa é observar como se deu a disseminação de uma mensagem postada neste serviço de microblog em relação a aspectos teóricos da chamada Teoria de Redes. Método: Utilizou-se a ferramenta "Where Does My Tweet Goes" para avaliar um tweet do político norteamericano Al Gore postado originalmente no dia cinco de junho de 2013. Os dados utilizados nesta pesquisa foram coletados pela própria ferramenta que busca as informações sobre as postagens diretamente na base de dados do Twitter. A análise dos dados foi feita de forma quantitativa a partir da própria ferramenta que identificou os retweets promovidos pelos seguidores de Al Gore. Resultados: Foi observado que a disseminação da mensagem especifica se deu de forma rápida, entretanto efêmera. 0 alcance da mensagem foi, de fato, potencializado pela rede atingindo mais do que o dobro dos seguidores originais de Al Gore sendo assim possivel quantificar a "viralidade" de uma postagem. Conclusão: 0 resultado desta pesquisa, ressaltada sua característica exploratória, sugere que a disseminação da informação no Twitter segue a tendência das denominadas "novas ciências" em redes sociais caracterizadas pela dinâmica dos elementos redes na sua construção e crescimento.
\end{abstract}

\section{Palavras-chave}

Microblogs. Twitter. Fluxo de informação. Disseminação da Informação.

\section{Introdução}

Com o advento da Internet e sua integração à vida cotidiana, as questões relativas ao uso das informações contidas neste espaço estão mudando do "quem está 'logado' no ambiente?" para uma análise mais aprofundada daquilo que as pessoas "fazem online". Existe um crescente reconhecimento de que a Internet está estimulando conexões e forjando novas ligações entre pessoas e organizações (HAYTHORNTHWAITE, 2005).

Cientistas sociais têm explorado a importância das redes sociais na disseminação da informação (GRANOVETTER, 1973) e nos processos de inovação (ROGERS, 2010). Outras tecnologias de comunicação modernas, tais como o e-mail, blogs e microblogs igualmente têm sido investigadas como espaços para a disseminação da informação (WU et al., 2004; GRUHL et al., 2004), e para a percepção de novas estratégias de busca por informação (ADAMIC; ADAR, 2005).

Pesquisas conduzidas por Haythornthwaite (2005) e Lerman e Gosh (2010) apontam que as interações entre pessoas deixariam de ser exclusivamente face a face para ser complementadas por mídias baseadas em texto e que estas ocorrem migram do espaço "virtual" para o "real" de acordo com a necessidade dos membros envolvidos em tais processos de mobilização.

Essa interação social se dá, de forma significativa, nas mídias sociais tais como Facebook, Instagram, Twitter, dentre outras. Nestes ambientes, as informações relativas aos usuários e suas relações com outros usuários são armazenadas em bases de dados com intuito de se tornarem cada vez mais atraentes. Estes mesmos serviços, disponibilizam ferramentas que promovem acesso as suas imensas bases de dados para análise empírica dos mais 
diversos fenômenos tais como o Facebook Developer $^{1}$, Twitter Developer ${ }^{2}$ e Netvizz ${ }^{3}$.

As áreas de investigação mais comuns na análise destes dados são a investigação da dinâmica da troca de informação entre indivíduos (VÁZQUEZ et al., 2006); o estudo dos comportamentos dos indivíduos (HOGG; LERMAN, 2009); a eficácia da recomendação de produtos em marketing viral (LESKOVEC; ADAMIC; HUBERMAN, 2007); as propriedades globais da propagação de mensagens de e-mail (WU et al., 2004; LIBENNOWELL; KLEINBERG, 2008); as postagens em blogs (LESKOVEC et al., 2007a); e a identificação de blogs influentes (GRUHL et al., 2004; LESKOVEC et al., 2007b).

$\mathrm{Na}$ maior parte destes estudos, a estrutura da rede formada não era visível aos pesquisadores, tendo sido inferida a partir do fluxo de informações de um indivíduo para outro. Identificar as características desse fluxo representava, portanto, um desafio, já anteriormente verificado por Haythornthwaite, voltado à compreensão sobre como a estrutura da rede afeta a dinâmica de propagação de informações sobre ela (HAYTHORNTHWAITE, 2005).

Serviços de microblog ${ }^{4}$, como o Twitter, se mostram como uma alternativa para estudar a dinâmica da disseminação de informações em redes sociais, uma vez que é reconhecido como uma importante fonte de informação para as pessoas comuns. Especificamente no Twitter, os usuários publicam ("tuitam") mensagens de texto curtas, não raro acompanhadas de hiperlinks para notícias ou mensagens de outros usuários (LERMAN; GOSH, 2010).

No Twitter as ligações entre usuários são criadas em pelo menos dois momentos: o primeiro ocorre quando usuários decidem seguir outros usuários e passam a ter acesso a todas as publica- ções feitas por ele; e o segundo momento quando o usuário deseja republicar (retweet/"retuitar") uma mensagem originalmente criada por algum outro usuário e que está visível em sua linha do tempo (timeline do Twitter).

Este trabalho apresenta um estudo exploratório com o objetivo de identificar as características da disseminação de uma postagem especifica no Twitter. Para isso, foram coletados os dados de uma postagem publicada no dia cinco de junho de 2013 pelo ex-candidato a Presidente dos Estados Unidos Al Gore.

A ferramenta utilizada para a coleta e análise dos dados foi a "Where Does My Tweet Go" senvolvida pelo arquiteto da informação francês Benoît Vidal - a qual tem como finalidade verificar o alcance de uma postagem. Essa ferramenta recupera os dados diretamente do Twitter mapeando a propagação das postagens entre os seguidores de determinado perfil e os seguidores dos seguidores, o que permite uma visualização em tempo real a partir dos dados de usuários reais.

Este trabalho visa contribuir com o entendimento das dinâmicas de propagação da informação na rede social, em especial sobre a contribuição das republicações que levam a mensagem para usuários até então "invisíveis" para o autor original. No âmbito da Ciência da Informação espera-se que os resultados - ainda que baseados em uma única ferramenta - possam colaborar com demais estudos que tenham como objeto de estudo o Twitter ou processos de disseminação de mensagens em redes sociais.

Além desta seção introdutória este trabalho possui outras quatro seções. A seção a seguir apresenta a literatura pertinente ao tema e todos os conceitos básicos necessários para o entendimento desta pesquisa. A seção seguinte apresenta a

\footnotetext{
${ }^{1}<$ www.developers.facebook.com $>$.

${ }^{2}<$ https://dev.twitter.com>.

${ }^{3}<$ https://tools.digitalmethods.net/netvizz/facebook/netvizz/>.

${ }^{4}$ Microblog é uma forma de publicação que permite aos usuários atualizações breves de texto. (http://www.pcmag.com/encyclopedia/ term/58092/microblog). O Twitter, por exemplo, permite mensagens de até 140 caracteres.

${ }^{5}<$ www.wdmtg.com>.
} 
metodologia utilizada para a realização da pesquisa, seguida da seção que apresenta os resultados da pesquisa, e da última seção voltada ao fechamento do trabalho e às discussões finais.

\section{O Fluxo informacional e a disseminação da informação}

Segundo Savi e Silve (2009, p.180) o fluxo informacional pode ser entendido como "o processo de transferência da informação de um emissor para um receptor" e se inicia a partir do momento em que um determinado indivíduo tem interesse em gerar um novo conhecimento ou, a partir da verificação das necessidades informacionais do receptor, o emissor inicia tal fluxo com o objetivo de satisfazer estas necessidades informacionais específicas.

Segundo Barreto (1998, p. 122) não é possível definir o ciclo informacional como uma forma linear de repasse de informação entre emissor e receptor, uma vez que ele se caracteriza como um processo disseminador de informações com o objetivo de mediar a comunicação. Nesse sentido, para que se compreenda a conjuntura dos fluxos de informação, se faz necessário delinear seu conceito que, segundo Greef e Freitas (2012, p. 40), pode ser entendido como uma sequência de eventos desde a geração da informação, por parte do emissor, até sua captação/assimilação/ aceitação pelo receptor, gerando saberes individuais e coletivos.

Frota e Quintão destacam a importância dos fluxos informacionais em ambientes online e, especificamente sobre a disseminação da informação, consideram que "esta comunicação em rede cumpre o papel de integração do transporte de fluxos, sejam eles materiais ou imateriais" (2010, p. 68). Anteriormente, Tomael e Marteleto (2006, p. 2) apontaram que, em ambientes em rede, o compartilhamento de informação e de conhecimento entre as pessoas é constante, pois as pessoas frequentemente gostam de compartilhar o que sabem. No contexto da comunicação em rede, portanto, a disseminação de informação tende a se intensificar movendo-se entre círculos sociais distintos que se tornam espaços de proliferação (TOMAEL, MARTELETO, 2006).

Sob esta perspectiva, Ferreira e Perucchi (2011, p. 453) destacam a necessidade de se buscar ferramentas e estruturas que facilitem o compartilhamento da informação, em especial aquelas apoiadas nos processos de comunicação eletrônica, uma vez que estas se mostram eficientes no processo de disseminação modificando estruturalmente o fluxo de informação e conhecimento. Neste particular, e já em 1999, Barreto considerava a informação online representada em fluxos de informação multidirecionados, nos quais o tempo entre as mensagens se aproxima de zero, a velocidade de difusão se acercando do infinito, e com os espaços de vivência sendo caracterizados pela não presença (1999, p. 5).

Paralelamente às discussões sobre difusão, Dixon (2000) afirma que a disseminação da informação é ação de tornar visível o conhecimento do indivíduo, enquanto que Lara e Conti (2003) consideram que disseminação assume formas variadas, dirigidas ou não, que geram inúmeros produtos e serviços de informação. Um indivíduo (ou grupo) pode divulgar determinada informação sem ter a intenção de atingir um público-alvo de forma específica. Desta forma, a disseminação assume um papel importante, pois a realidade em que se pretende que a informação atue e transforme, é multifacetada e formada por micronúcleos sociais com divergências profundas, que podem ser vistas como micronações isoladas por suas diferenças (BARRETO, 1999, p. 3).

Sob a perspectiva da distribuição da informação há um propósito de alcance dos mais variados tipos de usuários em diferentes contextos, permitindo que cada um trabalhe com a informação de forma individual e única. Considerando este fator nas redes sociais virtuais, Lerman e Gosh esclarecem que há diversas motivações para a obtenção, usos diferenciados e, consequentemente, diversas formas de difusão de uma mesma informação (2010). 


\section{A “nova ciência” em Redes Sociais: alguns elementos}

Segundo Franco (2008), a Sociologia tradicional está sendo ultrapassada em seus métodos e em seus marcos epistemológicos por uma nova orientação com enfoque nas redes sociais virtuais. Estas redes apresentam alguns fenômenos que, mesmo não sendo inéditos, só se mostraram claramente observáveis a partir das relações existentes nestas redes sociais. Dentre os principais "novos" conceitos investigados na temática de redes sociais virtuais podem ser destacados:

\section{o netweaving}

É possível afirmar que as redes sociais são constituídas por graus de distribuição variáveis entre a máxima centralização ( $0 \%$ de distribuição, onde apenas uma pessoa se comunica com todas as outras) e a máxima distribuição (100\% de distribuição, onde todos os membros da rede se conectam a todos os membros da mesma). Quando calculados, se o grau de distribuição for maior do que o grau de centralização é percebido a existência de uma rede distribuída (padrão todos-com-todos). Quando as redes se mostram mais centralizadas (padrão um-com-todos) estas formam hierarquias (FRANCO, 2008).

Diante desse contexto, o netweaving trata basicamente da articulação ou "animação" das redes e precisa necessariamente da conexão entre pessoas (redes distribuídas) e não apenas da ligação com um centro coordenador ou articulador (LITTELL; FISHER 2001). A diferença entre o netweaving, cujo foco se mostra em colaborar com os outros, e o networking, é que este último tem como foco vender algo para outros (MONESSON, 2007). Um netweaver se torna um recurso para outras pessoas que têm necessidades e problemas a resolver, incentivando-as a construir redes confiáveis para alavancar os negócios e/ou outras atividades sociais (MONESSON, 2007).

Vergili (2011) sugere que o maior desafio para a concretização do netweaving é a fonte de conhe- cimento, ou seja, a espontaneidade de formar laços de conhecimento com outros membros. Isso só pode ser proporcionado por meio da concepção de mecanismos de incentivo que permitam a participação espontânea do usuário uma vez que a disseminação de informações que ocorrem em redes sociais virtuais não são fenômenos triviais e simplórios (VERGILI, 2011).

\section{o swarming/enxameamento}

Franco (2008) afirma que o swarming ou enxameamento ocorre quando distintos grupos e tendências, não coordenados explicitamente entre si, vão aumentando o alcance e a virulência de suas ações. $\mathrm{O}$ enxameamento é um fenômeno que só é perceptível em linhas temporais longas, onde podem ser captados mais facilmente. O enxameamento é percebido nas grandes manifestações de massa e podem ser observados, caso haja possibilidade, a partir de conexões em tempo real. Sem tais recursos tecnológicos, esse fenômeno poderia levar dias ou até anos para se engendrar.

Isso não significa que eles ocorrem por causa da tecnologia. Se as pessoas não podem interagir uma com as outras e se não estiverem conectadas segundo um padrão distribuído, de pouco adianta as mais avançadas tecnologias interativas. A mesma afirmação vale para outros fenômenos típicos das redes que dependem do padrão de interação (dos graus de distribuição e conectividade) e não das tecnologias (dos recursos, dos dispositivos, das mídias) (WATTS, 2004).

Ainda segundo Watts, em uma rede existem nós que são capazes de ligar uma grande quantidade de outros nós que não estão interligados por pertencerem a sub-redes (clusters) diferentes. Tais nós, capazes de ligar grupos diferentes, são chamados de hubs e são caracterizados por estarem ligados a muitos outros nós de diversos clusters diferentes e possuírem uma distância média pequena relativamente a os outros nós da rede, o que pode ser medido por uma métrica chamada betweenness centrality. 


\section{o fenômeno do "Mundo Pequeno" ou crunching}

Alguns grupos sociais podem estar conectados a partir de caminhos muito curtos em suas redes. Quando pessoas tentam usar estes caminhos para alcançar outras pessoas que são socialmente distantes, eles estão se engajando em um tipo de pesquisa "focada" que é muito mais orientada na propagação e difusão de informações. Esse novo comportamento compreende a percepção sobre a maneira como as coisas fluem através das redes sociais (WATTS, 1999).

Franco (2008) aponta que a capacidade que redes sociais se mostram tão ricas em caminhos curtos é conhecida como o "Fenômeno do Mundo Pequeno" ou os "Seis Graus de Separação". O primeiro estudo empírico significativo do fenômeno do mundo pequeno foi realizado pelo psicólogo social Stanley Milgram, que sugeriu que a distância média entre dois indivíduos quaisquer no mundo real é de seis pessoas (EASLEY; KLEINBERG, 2012).

O experimento de Milgram demonstra dois fatos impressionantes sobre grandes redes sociais: a) que os caminhos curtos existem em abundância; e, b) as pessoas, agindo sem qualquer tipo de mapa global da rede, são eficazes em encontrar coletivamente esses caminhos curtos (EASLEY; KLEINBERG, 2012).

Para Franco (2008), outro fenômeno que ocorre como consequência do mundo pequeno é o crunching (encolhimento). Quanto mais caminhos curtos são apresentados pelas redes sociais, menor o "mundo" se torna. Então, quando o capital social de uma determinada rede aumenta, o "mundo" daqueles que fazem parte desta rede encolhe (crunch).

\section{Metodologia}

Para observar o processo de disseminação da informação e sua relação, em especial, com os as- pectos de enxameamento, republicação e "mundo pequeno" destacados no referencial teórico, fez-se um recorte no microblog Twitter.

Identificou-se a ferramenta Where Does My Tweet Go, que é capaz de "rastrear" o fluxo de uma postagem (tweet) específico a partir das republicações (retweets). Na versão paga existem funcionalidades interessantes tais como: a) a identificação de postagens relevantes; b) um cálculo para o enxameamento da informação utilizando um algoritmo proprietário chamado o spreadrank; e, c) a visualização das republicações. Esta última é a única funcionalidade disponível no modo gratuito, o que permitiu consolidar a escolha da ferramenta para o objetivo proposto nesta pesquisa.

Em seguida foi necessário escolher uma postagem específica para ser analisada. Para isto foi selecionada uma postagem do ex-candidato a presidente dos Estados Unidos Al Gore, cujo perfil no Twitter é @algore. A mensagem postada neste perfil, em 5 de junho de 2013, foi: "In digital era, privacy must be a priority. Is it just me, or is secret blanket surveillance obscenely outrageous?"6.

Esta mensagem foi escolhida por pertencer a um usuário que usuário possui 2.667.631 seguidores, o que representa quase $1 \%$ da totalidade de usuários do Twitter ${ }^{7}$, o que promove uma perspectiva de um rápido enxameamento da mensagem, ou seja, um alcance de um número considerável de usuários e que permaneça sendo republicada por um logo período de tempo. A análise dos dados foi realizada na própria ferramenta uma vez que ela coleta as informações na base de dados do Twitter e disponibiliza uma interface para a visualização da disseminação da informação e os dados referentes a cada "ponto" em que ela foi republicada.

\section{Resultados}

A Figura apresenta o fluxo da postagem estudada na ferramenta. Um dos resultados apresentados é o momento em que a última republicação foi fei-

\footnotetext{
${ }^{6}<$ https://twitter.com/algore/statuses/342455655057211393>.

${ }^{7}$ Dados recolhidos na plataforma Twitter no dia cinco de junho de 2013.
} 
ta. Isso representa o tempo em que a informação foi disseminada no Twitter e o quanto durou o "buzz" (burburinho) de uma determinada postagem. Pode-se verificar que a disseminação desta informação se dá em menos de um dia (o período de análise é de 19h34m).

Figura - Análise geral do tweet pesquisado - junho/2013

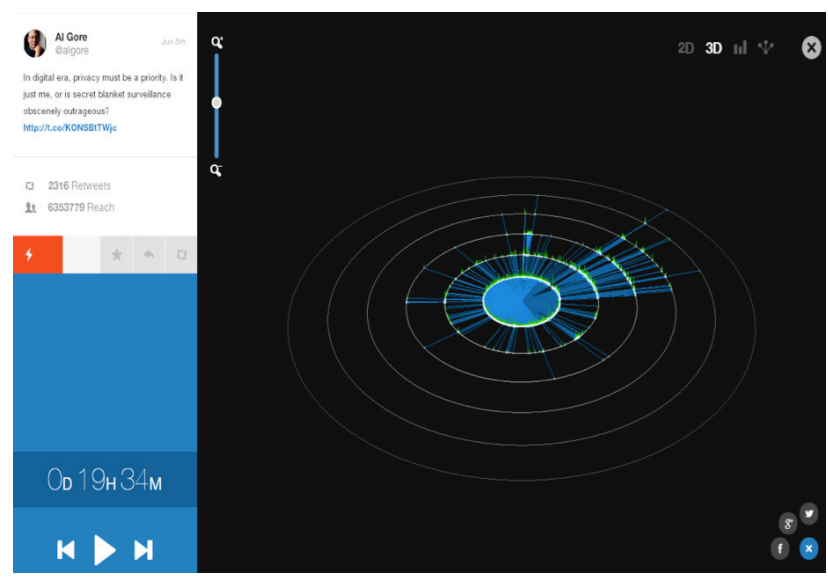

Fonte: os autores.

Al Gore tem 2.667.631 seguidores que representam o primeiro grau de separação de sua rede. Para esta postagem em particular, verificou-se que a sua disseminação se deu até o sexto grau de separação (seguidores dos seguidores). Neste último grau de separação apenas uma republicação foi feita.

Esta mensagem foi republicada 2.316 vezes ao longo de quase vinte horas. Destas, 1.211 retweets (mais de 50\%) ocorreram na primeira hora após sua publicação e $70 \%$ das republicações efetivadas nas três primeiras horas após a publicação original. Isso mostra como o enxameamento da postagem se mostra como muito rápida em um intervalo curto de tempo e tende a desacelerar lentamente. Percebeu-se que essa desaceleração do enxameamento também avança à medida que os graus de separação avançam. No primeiro grau, 890 republicações foram realizadas, no segundo grau 682, no terceiro 446, no quarto 259, no quinto 38 e, no sexto, apenas uma única republicação. O "mundo pequeno" de Al Gore é representado também em sua conta do Twitter. Por ser uma figura pública, cerca de $40 \%$ do alcance da postagem ocorre no primeiro grau de separação. Ou seja, aparentemente, as pessoas que po- dem se interessar por "Al Gore" já estão ligadas diretamente a ele.

Outro fato peculiar ao "mundo pequeno" de $\mathrm{Al}$ Gore é a ausência de hubs neste processo de disseminação. Neste caso, o próprio Al Gore foi responsável por atingir a maior parte dos usuários a partir da postagem original. $\mathrm{O}$ usuário com $\mathrm{o}$ maior alcance a partir de suas republicações foi @KimDotCom. Ele se encontra no primeiro grau do círculo de Al Gore. A partir dele, 337.284 usuários visualizaram a informação original. Este "novo" alcance representa os usuários que estão conectados com @KimDotCom, mas não estão no social de @AlGore. Este usuário representa pouco mais de $5 \%$ do alcance total das postagens e pouco mais de $2 \%$ das republicações (55) o que indica que ele não é um hub, pelo menos para esta mensagem.

\section{Considerações finais}

Esta avaliação do fluxo informacional, mais especificamente da disseminação de uma postagem específica realizada na plataforma de microblog Twitter e explorada com a ferramenta Where Does My Tweet Go, não se propõe a apontar a características generalizadas da disseminação da informação neste serviço, mas apenas apresenta - em um estudo exploratório - como uma postagem específica foi republicada ao longo do tempo e como se deu esse processo de disseminação.

Caso se considere o aspecto temporal das republicações, é possível perceber que, neste caso, a maior parte das republicações aconteceu na primeira hora após postagem original e a última republicação ocorreu em pouco mais de 19 horas, o que sugere um ciclo de vida bastante acelerado e curto para mensagens neste microblog. Para este perfil e tweet em particular verificou-se tal situação, mesmo que se destaque o fato de que $\mathrm{Al}$ Gore é uma pessoa pública, que circula no meio político norte-americano e, em tendo mais de dois milhões de seguidores na plataforma, possivelmente poderia atrair o interesse direto ou indireto de outras pessoas para suas postagens. 
Percebe-se, mesmo com a restrição no universo de análise, que há certa efemeridade das mensagens publicadas no Twitter. Pois, mesmo sendo uma postagem tratando de um tema político, emitida por uma figura pública com uma grande quantidade de seguidores, esta não se espalhou em uma duração maior de tempo. Resultados obtidos em mídias tradicionais, como o de Gruhl e colegas (2004), verificaram que notícias publicadas em sites de jornais e revistas podem ficar "vivas" por dias ou mesmo por semanas.

Ao se examinar o "mundo pequeno" de Al Gore identificou-se que $40 \%$ dos usuários que republicaram a mensagem situavam-se no primeiro grau de separação de sua rede. Este comportamento é esperado devido ao fato de que os usuários que conhecem/têm interesse naquilo que é relativo a Al Gore, já o seguem.

Vale observar que, ao se considerar que cerca de $60 \%$ das republicações foi feita por pessoas com as quais $\mathrm{Al}$ Gore possui conexão, a "audiência invisível" só visualizou a postagem por que existia um caminho curto entre estes usuários "invisíveis" que republicaram o tweet. Uma vez que $\mathrm{Al}$ Gore tinha, no momento da análise, 2,6 milhões de seguidores, essa audiência invisível quase que triplicou o alcance da postagem, atingindo cerca de 6,3 milhões de usuários.

Por se tratar de uma pessoa pública, era esperado que esta postagem encontrasse outro usuário e que, a partir deste, as republicações retomassem o fôlego e atingissem outras sub-redes para além do acesso direto do perfil original, isso não ficou aparente no ciclo do experimento.

Ainda que se destaque o aspecto exploratório desta investigação - restrita a uma postagem e a uma ferramenta (em sua funcionalidade gratuita) - foi possível apontar alguns indícios sobre o processo de disseminação da informação no Twitter em relação a algumas características da chamada Teoria de redes. Porém, uma série de lacunas permanece aberta e são passíveis de investigações futuras.

O primeiro trabalho futuro seria ampliar a quantidade de postagens investigadas e a partir daí realizar algum tipo de tratamento estatístico para descobrir correlações e padrões das mensagens publicadas no Twitter. Este tipo de pesquisa pode revelar com um pouco mais de precisão como ocorre a disseminação da informação naquele serviço de microblog.

Utilizar métricas apropriadas na análise de redes sociais como centralidade, e outras afins para investigar o caráter social das mensagens do Twitter. Algumas das métricas comuns em análise de redes sociais não serão possíveis de se investigar usando esta ferramenta tais como centralidade, densidade ou qualquer outra que envolva a múltiplos usuários e suas ligações a partir de uma mensagem.

Investigar em um número maior de postagens, os mesmos fenômenos investigados neste trabalho, tais como o enxameamento, alcance, graus de separação e a presença de hubs com o intuito de investigar e, se possível generalizar, como se dá o processo de disseminação da informação em si e o papel dos usuários neste processo. Neste particular, verificar a existência de outras ferramentas de coleta/análise que possam, igualmente, permitir estudos comparativos.

Finalmente, outra preocupação na temática de pesquisa se refere aos processos de avaliação da importância da preservação das mensagens publicadas no Twitter, uma vez que as mídias sociais virtuais hoje são tratadas pelos usuários como espaços para messaging 8 , o que resulta em um grande e crescente volume de informações e na dificuldade de se garantir a recuperação do que não é considerado "recente".

\footnotetext{
${ }_{8}^{8}$ Messaging (ou text messaging) é um sistema de comunicação assíncrona baseada em mensagens curtas iniciadas a partir dos SMSs de telefones celulares e popularizadas pelos messengers (ICQ e MSN) (http://www.pcmag.com/encyclopedia/term/52795/text-messaging). Hoje, redes sociais como Twitter, Facebook, Snapchat, Whatsapp funcionam com base nesta estrutura.
} 


\section{Referências}

ADAMIC, L.; ADAR, E. How to search a social network. Social Networks, v. 27, n. 3, p. 187-203, 2005. Disponível em: <www.cond.org/socsearch.pdf $>$. Acesso em: 10 fev. 2014.

ALVES, C. D. Informação na twitosfera. Revista Digital de Biblioteconomia e Ciência da Informação, v. 9, n. 1, p. 92-105, 2011. Disponível em: <http://polaris. bc.unicamp.br/seer/ojs/index.php/rbci/article/ view/497>. Acesso em: 21 jun. 2014.

BARRETO, A. Os destinos da Ciência da Informação: entre o cristal e a chama. DataGramaZero: Revista de Ciência da Informação, v.9, n.2, dez. 1999. Disponível em: <http://www.ies.ufpb.br/ojs/index.php/ies/article/ view/397/318>. Acesso em: 21 abr. 2014.

DIXON, N. M. Common Knowledge: how companies thrive by sharing what they know. Harvard Business School Press. Boston. 2000.

DRUCKER, P. Além da revolução da informação. HSM Management. n. 18, jan./fev. 2000. p. 48-55.

EASLEY, D.; KLEINBERG, J. Networks, crowds, and markets: reasoning about a highly connected world. 2012 .

FERREIRA, T. E. L. R.; PERUCCHI, V. Gestão e o fluxo da informação nas organizações: um ensaio a partir da percepção de autores contemporâneos. Revista ACB, v. 16, p. 446-463, 2011. Disponível em: <http://revista. acbsc.org.br/racb/article/view/781/pdf_61>. Acesso em: 21 abr. 2014.

FRANCO, A. Escola de Redes: Novas visões sobre a sociedade, o desenvolvimento, a internet, a política e o mundo globalizado. Curitiba: Escola-de-Redes, 2008.

FROTA, M. G. da C.; QUINTÃO, P. G. Fluxos informacionais para o monitoramento da Convenção dos Direitos da Criança: a atuação da rede NGO Group for CRC. Encontros Bibli: Revista Eletrônica de Biblioteconomia e Ciência da Informação, v. 15, p. 66-83, 2010. Disponível em: <https:// periodicos.ufsc.br/index.php/eb/article/view/15182924.2010v15n29p66>. Acesso em: 21 abr. 2014.

GRANOVETTER, M. S. The strength of weak ties. American Journal of Sociology, Chicago, v. 78, n. 6, p. 1360-1380, 1973.

GREEF, A. C.; FREITAS, M. C. D. Fluxo enxuto de informação: um novo conceito. Perspectivas em Ciência da Informação, v. 17, p. 37-55, 2012. Disponível em: <http://portaldeperiodicos.eci.ufmg. br/index.php/pci/article/view/1246>. Acesso em: 21 abr. 2014.

GRUHL, D.; GUHA, R.; LIBEN-NOWELL, D.; TOMKINS, A. Information diffusion through blogspace. In: INTERNATIONAL CONFERENCE ON WORLD WIDE WEB, 13., 2004, Nova York. Proceedings... Nova York: ACM, 2004. p. 491-501.

HAYTHORNTHWAITE, C. Social networks and Internet connectivity effects. Information, Community \& Society, v. 8, n. 2, p. 125-147, 2005. Disponível em: <http://www.tandfonline.com/doi/ abs/10.1080/13691180500146185\#.U1bWB-ZdUZ4>. Acesso em: 21 abr. 2014.

HOGG, T.; LERMAN, K. Stochastic models of usercontributory web sites. In: INTERNATIONAL CONFERENCE ON WEBLOGS AND SOCIAL MEDIA, 3., 2009, San José. Proceedings... San José: ICWSM, 2009.

HUNG, E. S.; CALDERÓN, C. A. Online opinion leaders in Latin America and the Middle East: the case of the Top 20 most-viewed twitter users. Informação \& Sociedade, v. 23, n. 3, 2014. Disponível em: <http:// www.biblionline.ufpb.br/ojs/index.php/ies/article/ view/17818>. Acesso em: 21 jun. 2014.

LARA, M. L. G. ; CONTI, V. L. Disseminação da informação e usuários. São Paulo em Perspectiva, v. 17, n. 3-4, p. 26-34, 2003. Disponível em: <http://www. scielo.br/pdf/spp/v17n3-4/a04v1734.pdf $>$. Acesso em: 21 abr. 2014

LERMAN, K.; GHOSH, R. Information contagion: An empirical study of the spread of news on Digg and Twitter social networks. In: INTERNATIONAL CONFERENCE ON WEBLOGS AND SOCIAL MEDIA, 4., 2010, Washington. Proceedings... Washington: ICWSM, 2010.

LESKOVEC, J.; ADAMIC, L. A.; HUBERMAN, B. A. The dynamics of viral marketing. ACM Transactions on the Web, v. 1, n. 1, 2007.

LESKOVEC, J.; KRAUSE, A.; GUESTRIN, C.; FALOUSTOS, C.; VANBRIESSEN, J. Costeffective outbreak detection in networks. In: ACM SIGKDD INTERNATIONAL CONFERENCE ON KNOWLEDGE DISCOVERY AND DATA MINING, 13., 2007. Proceedings... SIGKDD, 2007.

LESKOVEC, J.; McGLOHON, M.; FALOUTSOS, C.; GLANCE, N.; HURST, M. Cascading behavior in large blog graphs. In: SIAM INTERNATIONAL CONFERENCE ON DATA MINING,7., 2007. 
Minnesota. Proceedings... Minnesota, USA, SIAM. 2007.

LIBEN-NOWELL, D.; KLEINBERG, J. Tracing information flow on a global scale using Internet chain-letter data. Proceedings of the National Academy of Sciences, v. 105, n. 12, p. 4633-4638, 2008.

LITTELL, R. S.; FISHER, D. Power Netweaving: 10 secrets to successful relationship marketing. National Underwriter Company, 2001.

MONESSON, E. P. Netweaving-a powerful tool for developing relationships. CPA Practice Management Forum, v. 3, p. 12, 2007. Disponível em: <http:// heinonline.org/HOL/LandingPage?handle=hein . journals $/$ cpamanf3\&div $=45 \&$ id $=\&$ page $=>$. Acesso em: 21 abr. 2014.

ROGERS, E. M. Diffusion of innovations. Nova York: Freepress, 2010.

SAVI, M. G. M.; SILVA, E. L. da. O fluxo da informação na prática clínica dos médicos residentes: análise na perspectiva da medicina baseada em evidências. Ciência da Informação, v. 38, n. 3, p. 177-191, 2009. ISSN 0100-1965. Disponível em: <http://www.brapci.ufpr.br/documento. php?dd0 $=0000008834 \& d d 1=c 6 c 8 c>$. Acesso em: 21 abr. 2014.

TOMAÉL, M. I.; MARTELETO, R. M. Redes sociais: posições dos atores no fluxo da informação. Encontros Bibli: Revista Eletrônica de Biblioteconomia e Ciência da Informação, no esp, p. 75-91, 2006. Disponível em: <https://periodicos.ufsc.br/index.php/eb/article/ view/1518-2924.2006v11nesp1p75>. Acesso em: 21 abr. 2014.

VÁZQUEZ, A.; OLIVEIRA, J. G.; DEZSO, Z.; GOH, K.; KONDOR, I.; BARÁBASI, A. Modeling bursts and heavy tails in human dynamics. Physical Review, v. 73, n. 3, 2006 .

VERGILI, R. Relação entre relevância da informação e articulação de redes por profissionais de comunicação. Revista Eletrônica da Pós-Graduação da Cásper Líbero, v. 3, n. 1, p. 1-11, 2011. Disponível em: <http:// www.revistas.univerciencia.org/index.php/comtempo/ article/view/7572>. Acesso em: 21 abr. 2014.

WU, F.; HUBERMAN, B. A.; ADAMIC, L. A.; TYLER, J. R. Information flow in social groups. Physica A: statistical mechanics and its application, v. 337, n. 1, p. 327-335, 2004.
Information dissemination on Twitter: an exploratory analysis of the informational flow of retweets

\section{Abstract}

Introduction: It presents the process of dissemination of information on the microblog service Twitter considering the "retweets" made by users that spread posts created by other users. The goal of this research was to observe how the dissemination of one specific tweet posted in this Microblog service developed through a cycle of time and in regard to some aspects derived from the so called Network Theory. Method: It was used the "Where Does My Tweet Goes" tool to evaluate one post wrote by Al Gore posted on Twitter at June the 5th., 2013. The tool collects the data automatically from the Twitter database and a quantitative analysis was performed using the same tool in order to identify the ripple effect of the "retweets" provided by Al Gore's followers. Results: It was observed that the dissemination of the post was quickly, however ephemeral. The reach of the message was, in fact, enhanced by the network effect reaching twice (and more) Twitter users when compared with the original profile followers. It showed a "viral" aspect of the network in respect of this particular post. Conclusions: The results of this research suggests that the spread of information on Twitter follows the trends of the so called network "new science", which includes social platforms characterized by the dynamic of its elements, design and growth.

\section{Keywords}

Microblogs. Twitter. Information flow. Information Dissemination. 
Recebido em 1 abril 2014

Aceito em 2 julho 2014

Sobre os autores:

\section{Célio Andrade Santana Júnior}

Bacharel em Ciências da Computação - UFPE, Mestre em Engenharia de Computação - UPE, Doutor em Ciências da Computação - UFPE. Professor Adjunto - UFPE.

celio.santana@gmail.com

\section{João Pedro Silva Albuquerque}

Graduando em Gestão da Informação - UFPE.

joao.pedro1221@gmail.com

\section{Fabiola Souza Queiroz}

Graduanda em Gestão da Informação - UFPE.

fabiolaqroz@gmail.com

\section{Steffane Ramires Lima}

Graduanda em Gestão da Informação - UFPE.

steffane.ramires@gmail.com

\section{Como citar este artigo:}

SANTANA JÚNIOR, C. A.; ALBUQUERQUE, J. P. S.; QUEIROZ, F. S.; LIMA, S. R. A disseminação da informação no Twitter: uma análise exploratória do fluxo informacional de retweets. AtoZ: novas práticas em informação e conhecimento, Curitiba, v. 3, n. 1, p. 50-59, jan./jun. 2014. Disponivel em: <http://www.atoz.ufpr.br>. Acesso em: 